\title{
New York Society for Speech and Voice Therapy
}

\section{Meeting April 5th 1961}

Annual Meeting: At the Annual Meeting of the Society the following officers were elected: President: Emil Froeschels, M. D., First Vice-President: Deso A. Weiss, M. D., Second VicePresident: Shulamith Kasteín, Treasurer: Erika Mohr, M. D., Recording Secretary: Fríedrích S. Brodnitz, M. D., Corresponding Secretary: Helen Beebe.

Lecture: Emil Froeschels, M. D., New Viewpoints on Stuttering. In place of the scheduled speaker who was ill, Dr. Froeschels reported on several aspects of stuttering. In a paper in Logopedie en Phoniatrie a symptom of some stutterers has been described: the stutterers mind is so much concentrated on a speech difficulty that he is totally unware of signals (such as the therapist's raised right hand or tapping on the desk) to which he has been asked to react with stopping speaking (temporary pronunciation monomania). Beebe has previously written about sentence mindedness. She and the lecturer have tried to explain the connection between this and the monomania of stutterers. The stutterer destroys with this momentary monomania the Gesammtvorstellung ( Wundt) of the sentence (before the stuttering attack) in order to restore the Gesammtvorstellung. The lecturer also dealt with the telephone difficulties of many stutterers which may have many possible explanations. One of these seems to be in fact that while in usual speaking situations the "speaker" has some choice of whether he chooses to speak or not, on the telephone he has to speak, there is no other choice.

Meeting May 3rd 1961

Lecture: Jon Eisenson, Ph. D., Language Modifications and Right Cerebral Damage - Summary and Interpretation of Results.

A group of adult subjects with right cerebral damage and others free from such damage were examined with a modified and shortened version of a test battery that

80

\section{Societates}

included the Vocabulary and Minkus Sentences of the Stanford-Binet, Form L, and selected items of the Institute of Educational Research Tests, CAVD. The following general conclusions seem to be justified by the data:

Right cerebral damaged subjects are inferior on a quantitative and qualitative basis to nondamaged persons in their ability to define the words of the Stanford-Binet Form L Vocabulary Test.

Right cerebral damaged adults are inferior to those without damage in their ability to complete the Minkus Sentences of the Stanford-Binet, Form L. These sentences require the use of abstract words for their acceptable completion.

Right brain damaged subjects are inferior to those without brain damage in their recognition vocabulary ability as measured by vocabulary items selected from the IER, CAVD Inventory. Right brain damaged adults are inferior to those without damage in their ability to complete sentences selected from the IER, CAVD Inventory with and without multiple choice possibilities. 
According to our interpretation of the data, we think the following speculations if not conclusions are in order:

Right cerebral damage is associated with language decrement in both productive and recognition test situations.

Right cerebral damage is associated with increased difficulty in the individual's adjustment to the linguistic formulations of another person.

If the test items are considered measures of verbal intelligence, then right cerebral damage is associated with reduced intellectual proficiency if not with an absolute decrement in intelligence. Beyond these general observations, the principal investigator obtained some impressions and clinical judgments arising out of the administration of this inven tory to a considerable number of the cases included in this report. It is his belief that the right hemisphere is importantly involved in language behavior on the level of generalization and conceptualization. Manifest impairments associated with right cerebral damage include a lowering of the level of generalizing ability, a decrease in the ability or likelihood that an abstract attitude, required for the best level of linguistic performance, will take place according to the needs of the situation. In this respect the right brain damaged subjects express difficulty in what Dr. Kurt Gold stein would refer to as the abstract attitude. Such an impairment is considered by Dr. Goldstein to be the fundamental feature of aphasic impairment. The principal investigator was also impressed with the difficulty experienced by the experimental subjects in changing their sets in their attempts at word definitions. Once a verbal set was established, it tended to be used for a succession of words, often at the expense of producing a poor definition, or certainly a poorly worded or even distorted definition. Friedrích S. Brodnitz, Rec. Secretary

Corrigendum

Die im Literaturverzeichnis der Arbeit von M. H. Kaulhausen in Vol. 13, Nr. 3, Seite 232 dieser Zeitschrift zitierte Arbeit:

Kuhlmann, W.: Sprache als Bestand und Vollzug, ist nicht im Selbstverlag erschienen, sondern in Bielefelds Verlag, Freiburg 1959. 